\title{
Pharmaco-Magnetic Resonance as a Tool for Monitoring the Medication-Related Effects in the Brain May Provide Potential Biomarkers for Psychotic Disorders
}

\author{
Katrin Aryutova (D) and Drozdstoy Stoyanov *(D) \\ Department of Psychiatry and Medical Psychology, Research Institute, Medical University Plovdiv, \\ 4002 Plovdiv, Bulgaria; katrin.aryutova@phd.mu-plovdiv.bg \\ * Correspondence: drozdstoy.stoyanov@mu-plovdiv.bg
}

\section{check for} updates

Citation: Aryutova, K.; Stoyanov, D. Pharmaco-Magnetic Resonance as a Tool for Monitoring the Medication-Related Effects in the Brain May Provide Potential Biomarkers for Psychotic Disorders Int. J. Mol. Sci. 2021, 22, 9309 https://doi.org/10.3390/ ijms22179309

Academic Editor: Juan

F. Lopez-Gimenez

Received: 10 July 2021

Accepted: 25 August 2021

Published: 27 August 2021

Publisher's Note: MDPI stays neutral with regard to jurisdictional claims in published maps and institutional affiliations.

Copyright: (c) 2021 by the authors. Licensee MDPI, Basel, Switzerland. This article is an open access article distributed under the terms and conditions of the Creative Commons Attribution (CC BY) license (https:// creativecommons.org/licenses/by/ $4.0 /)$.
Abstract: The neurodegenerative and neurodevelopmental hypotheses represent the basic etiological framework for the origin of schizophrenia. Additionally, the dopamine hypothesis, adopted more than two decades ago, has repeatedly asserted the position of dopamine as a pathobiochemical substrate through the action of psychostimulants and neuroleptics on the mesolimbic and mesocortical systems, giving insight into the origin of positive and negative schizophrenic symptoms. Meanwhile, cognitive impairments in schizophrenia remain incompletely understood but are thought to be present during all stages of the disease, as well as in the prodromal, interictal and residual phases. On the other hand, observations on the effects of NMDA antagonists, such as ketamine and phencyclidine, reveal that hypoglutamatergic neurotransmission causes not only positive and negative but also cognitive schizophrenic symptoms. This review aims to summarize the different hypotheses about the origin of psychoses and to identify the optimal neuroimaging method that can serve to unite them in an integral etiological framework. We systematically searched Google scholar (with no concern to the date published) to identify studies investigating the etiology of schizophrenia, with a focus on impaired central neurotransmission. The complex interaction between the dopamine and glutamate neurotransmitter systems provides the long-needed etiological concept, which combines the neurodegenerative hypothesis with the hypothesis of impaired neurodevelopment in schizophrenia. Pharmaco-magnetic resonance imaging is a neuroimaging method that can provide a translation of scientific knowledge about the neural networks and the disruptions in and between different brain regions, into clinically applicable and effective therapeutic results in the management of severe psychotic disorders.

Keywords: schizophrenia; psychosis; cognitive symptoms; neurotransmission; dopamine; glutamate; brain connectivity; pharmacological magnetic resonance imaging

\section{Introduction}

Psychosis is not a nosological entity, but rather a clinical condition consisting of numerous symptoms that may be a common clinical outcome of a variety of causes. While the concept and definition of psychosis is defined by the core clinical symptoms of delusions, hallucinations, and disorganized thinking, these symptoms are most likely the common final consequences of a variety of different etiopathogenetic pathways, which may all lead to an analogous clinical picture [1].

Schizophrenia and other psychotic disorders are a heterogeneous group of mental illnesses that are frequently categorized together for practical reasons. However, schizophrenia is the most prevalent, debilitating, and socially significant disorder among this group [2] Schizophrenia is distinguished by a wide range of psychopathological features: positive symptoms (psychotic symptoms: delusions, hallucinations and disorganized behavior), negative symptoms (avolition, alogia, autism, affect flattening, social disengagement, etc.), and cognitive impairment (attention, memory and executive functions deficits) [3]. Positive 
symptoms usually resolve and relapse, although many individuals maintain protracted psychotic symptoms. Negative and cognitive symptoms are often persistent and are correlated with long-term consequences on social function [4]. The first episode of psychosis generally occurs in late adolescence or early adulthood, although it is commonly precipitated by a prodromal stage [5] and premorbid cognitive deficits [4].

The diagnosis of schizophrenia is purely clinical, most often made after the first manifestation of psychotic symptoms [6]. In practice, the criteria of the Diagnostic and Statistical Manual of Mental Disorders-5th edition (DSM-V) [7] and the International classification of diseases-10th division (ICD-10) [8] are the "gold standard" used for diagnostic purposes. DSM-V and ICD-10 are guidelines with high reliability [9], as they are applied worldwide by clinicians. However, these manuals, as well as the available psychometric tools (questionnaires, assessment/self-assessment scales), are considered unconventional diagnostic methods for the standard medical framework [10]. This is due to the lack of evidence-based etiological explanations for schizophrenia and other psychotic disorders [11]. Psychiatrists are the only medical professionals who do not examine the organ they are treating, but instead rely on observations of behavior, reported complaints from the patient and/or third parties, and their willingness to draw conclusions about their patients' personal experiences [12]. This inevitably compromises both the diagnostic and therapeutic process, which may be at the root of the treatment failures that are a common obstacle among schizophrenic patients.

Despite all the described shortcomings, psychiatry is currently in its "heyday" due to the variety of neuroimaging techniques that offer opportunities to study structural and functional aberrations in the central nervous system (CNS). Combining psychopharmacology with functional magnetic resonance imaging (fMRI) in the study of central psychopharmacological mechanisms, could be a successful translational strategy in the search for biomarkers for the validity of psychiatric diagnosis and treatment monitoring in clinical practice.

This review will examine the etiological theories of schizophrenia, the current methods for identifying biomarkers by neuroimaging tools, the possibilities of incorporating research findings into clinical practice, and the potential benefits of applying interdisciplinary efforts in the management of schizophrenia, emphasizing translational neuroscience. We will visualize our desire to combine psychopathological, psychopharmacological and neuroimaging techniques with the ultimate goal of finding the optimal therapeutic method that could successfully treat not only the positive but also the negative and cognitive symptoms that cause severe disability among schizophrenic patients.

\section{Methods}

Studies were searched via Google Scholar and PubMed databases without taking into account the date of publication. Potential candidate studies were identified first using the following search word combinations: etiological theories-relevant (schizophrenia, neurodevelopment hypothesis, neurodegenerative hypothesis, biochemical, neurotransmission, dysconnectivity hypothesis), and MRI-relevant (fMRI, blood-oxygen-level-dependent (BOLD), functional imaging, connectivity, rest, or resting, task, pharmacological MRI). Reference lists of retrieved studies were also searched manually to find additional potential studies of relevance to match the initial keywords set.

\section{Results}

\subsection{Etiological Theories of Schizophrenia}

Various theories on the origins of schizophrenia have been proposed in the past, including the supernatural, somatogenic, and psychogenic theories. According to the supernatural theory, psychotic phenomena are attributed to spells, sins, and the soul's possession by evil and demonic spirits. According to the somatogenic theory, behavioral disturbances arise as a result of somatic disease, genetic anomalies, brain injury, or 
metabolic imbalance. Psychogenic theory is concerned with psychotraumatic or stressful events that result in maladaptive behavior [13].

In modern times, with the understanding of the basic and specific biological mechanisms in the CNS, several etiological directions have been formed, which are supported by the relevant genetic, clinical, neuroimaging and especially psychopharmacological observations on the course of psychotic disorders.

\subsubsection{Neurodevelopment vs. Neurodegeneration}

Since Bender [14] coined the term "developmental encephalopathy" in 1947 to describe schizophrenia, numerous studies have revealed strong links between delayed motor development in children and the onset of the illness [15-17]. This finding might indicate aberrant functional development of the cortical-subcortical brain circuits, which is a predictor of future behavioral disorders (in later childhood and adolescence) [18] as well as an inability to organize the brain structure and function properly in adulthood $[19,20]$. Longitudinal studies have reported that people with schizophrenia develop cognitive impairment, especially in executive functions, even before the full clinical manifestation of psychosis [21-23]. These findings support the view that neurodevelopmental abnormalities play a central role in the etiopathogenesis of schizophrenia [24].

Numerous longitudinal studies, on the other hand, have discovered a progressive decrease in cortical thickness over the course of the disease, which correlates with the affected individuals' ongoing impairment in cognitive and social functioning [25-27]. This concept underpins the neurodegenerative hypothesis, which states that schizophrenia is caused by an organic neurodegenerative process that manifests itself in an individual's behavior through the course of the illness and is most active in the early stages of the disease [28]. However, an obstacle to the acceptance of the neurodegenerative hypothesis is antipsychotic medications, which exhibit a significant effect on brain structure and function of schizophrenic patients. In order to avoid this confounding factor, Lin et al. [29] used MRI to measure the cortical thickness in first-episode and treatment-naive patients with schizophrenia and discovered that the parietal, frontal, temporal, and cingulate zones exhibited a significant age-related reduction of cortical thickness compared to healthy controls, which supports the neurodegenerative hypothesis.

Some scientists propose a conceptual model that consists of a set of pathological mechanisms that occur during the stages of neurodevelopment, as well as later emerging (during the first psychotic episode) brain-degenerative processes, which, when combined with the same causal factors, eventually at some point lead to the clinical manifestation of schizophrenia [30].

\subsubsection{Biochemical Explanation of Psychosis}

In the second half of the twentieth century, the focus shifted from psychogenic to neurobiochemical theory, thanks to the advent of neuroleptics. Their action on dopamine D2-receptors in mesolimbic and mesocortical structures underlies the "dopamine hypothesis" [31] for schizophrenia, rejecting the psychodynamic "schizophrenogenic mother" $[32,33]$. The realization that schizophrenic psychosis is not a consequence of a wrong model of child rearing, but a true neurochemical disorder caused by a dysfunction in central dopaminergic neurotransmission [31,34], completely changed the understanding of the origin of psychosis.

The classical dopamine hypothesis for schizophrenia suggests that hyperdopaminergia in the mesolimbic system causes psychotic symptoms [35] and hypodopaminergia in the mesocortical pathway is the reason for negative symptoms. This hypothesis is supported by the correlation between the action of antipsychotic drugs and their efficacy in blocking dopamine D2 receptors [36], as well as by the psychotic phenomena triggered by the dopamine agonists [37]. Studies with amphetamine (psychomimetic drug) in untreated patients with schizophrenia have shown hyperdopaminergic activity in the striatum. Using single-photon emission computed tomography (SPECT) neuroimag- 
ing, amphetamine-induced hyperdopaminergia was found to be significantly higher in patients with schizophrenia compared to healthy controls [38-41]. The same abnormal effect has been found in patients in their first psychotic episode who had never taken antipsychotics [39]. In addition, this hypothesis is supported by clinical and research observations of epileptic seizures caused by lesions in the limbic regions that lead to florid psychotic production [42], as well as observations on individuals with tumors in the limbic structures [43].

The classical dopamine hypothesis is presented on Figure 1.

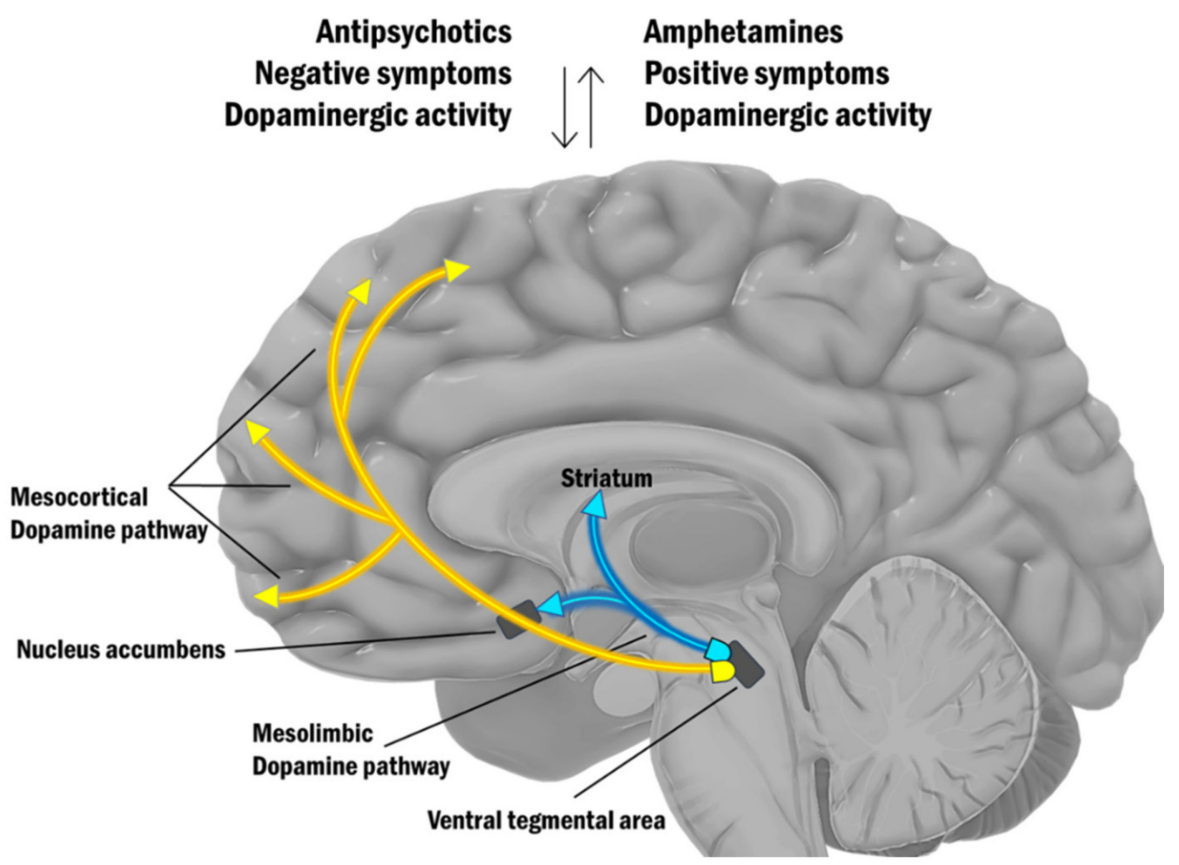

Figure 1. The dopamine hypothesis for schizophrenia.

Although the dopamine hypothesis has contributed significantly to the understanding of the clinical effects of psychostimulants, as well as to the introduction of many molecules with antipsychotic effects, it has nevertheless led to certain limitations [44]. For example, the perception of the dopamine hypothesis as an absolute etiological framework limits investigations in neurobiology, shifting researchers' focus mainly to investigate brain areas with rich dopaminergic neurotransmission and somewhat ignoring findings in other potentially significant areas in the brain. The disturbances of the dopaminergic neurotransmission and the therapeutic efficacy of D2-antagonists are insufficient for a systematic understanding of the complex psychopathology of schizophrenia. Although it provides a satisfactory explanation for the genesis of psychotic symptoms, the disadvantage of the dopamine hypothesis is its inability to explain cognitive and partly negative schizophrenic symptoms, which are responsible for the significant deterioration in schizophrenic patients' ability to work and social disengagement [45].

About four decades ago, an alternative etiological formulation for schizophrenia was postulated based on the action of "dissociative anesthetics," a class of psychomimetic drugs that includes phencyclidine (PCP) and ketamine. These substances are glutamatergic antagonists that act by blocking the glutamate receptor of the $N$-methyl- $D$-aspartate (NMDA) type [44]. Unlike dopamine agonists (amphetamines), NMDA antagonists such as PCP and ketamine induce positive, negative, and cognitive symptoms that are virtually indistinguishable from those seen in schizophrenia [46-49]. In addition, it has been suggested that impaired dopaminergic neurotransmission in schizophrenia may itself be secondary to abnormal NMDA-receptor neurotransmission [50,51]. Amphetamine-induced central hyperdopaminergic activity in schizophrenia has already been shown to result from 
disturbances in the glutamatergic neuronal systems that regulate dopaminergic cellular activity [41]. In addition, abnormalities of glutamatergic afferent neurons from the prefrontal cortex (PFC) to the dopaminergic subcortical areas of the midbrain are likely to be associated with this abnormal regulation, given the evidence of deficiencies in PFC function in schizophrenia [52-55]. In this sense, dopamine is regulated by cortical glutamate in two ways: as a direct excitator and as an indirect inhibitor. Typically, in healthy individuals, the descending glutamatergic pathway exhibits excitatory influence on the mesocortical dopamine pathway, guiding higher brain regions in the cortex. Dopamine misfiring may lead to cognitive impairments and symptoms of schizophrenia if NMDA receptors in the midbrain are malfunctioning. The glutamate neurons that connect to the dopaminergic neurons in the limbic system, on the other hand, have a gamma-aminobutyric acid (GABA) interneuron between them. GABA acts as a brake by inhibiting the release of dopamine. Excess dopamine can contribute to the occurrence of positive symptoms of psychosis if this break is removed, for example, by less glutamatergic activity (Figure 2).

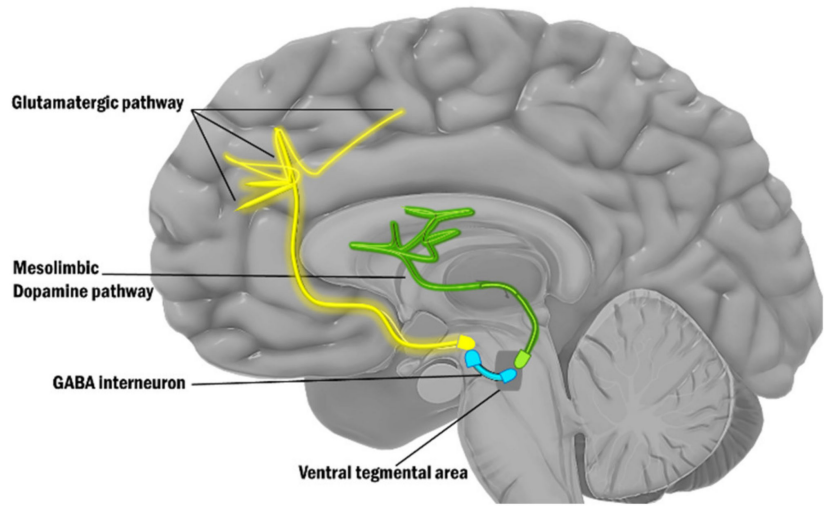

(a)

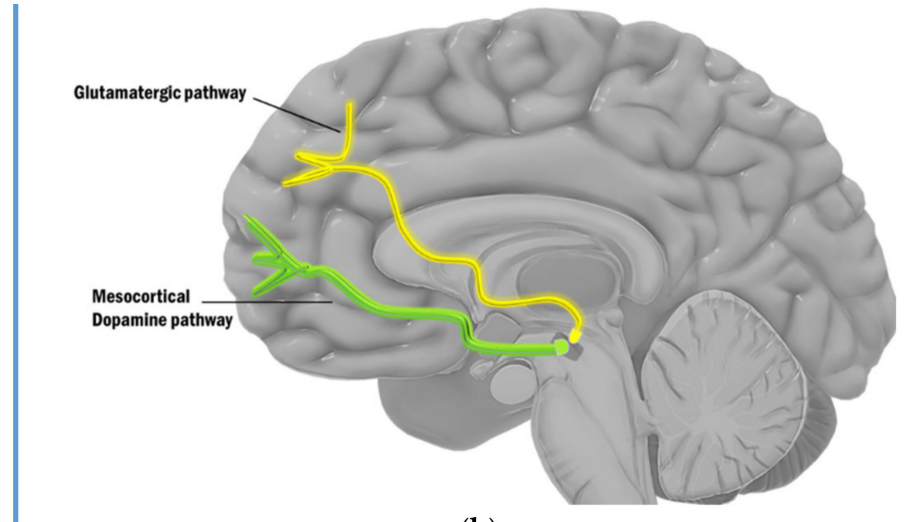

(b)

Figure 2. Dopamine pathways' regulation by the glutamate pathways (green-dopaminergic; yellow-glutamatergic; blue-GABA-ergic): (a) Descending glutamatergic pathway connect to the dopaminergic mesolimbic system via a GABA interneuron between them. In the case of disruption, psychotic symptoms emerge; (b) The descending glutamatergic pathway exhibits excitatory influence on the mesocortical dopamine pathway, and, in the case of disruption, cognitive deficits emerge.

Another interesting point of view for psychosis was presented back in 1986 by Robinson and Becker [56] who suggested that at least two distinct psychotic syndromes can result from chronic amphetamine administration. The first condition known as "amphetamine neurotoxicity" is caused by long-term exposure to increased amphetamine concentrations in the brain and is described by the term "hallucinatory-like" behavior and is associated with brain damage that results in a depletion of striatal dopamine and other brain monoamines. The second condition known as "behavioral sensitization" is caused by the administration of modest doses of amphetamine repeatedly and is defined as a gradual enhancement in numerous amphetamine-induced behaviors without causing brain damage or monoamine depletion.

Neuronal sensitization is a universal characteristic in the development of schizophrenia. Incentive learning is considered to be at the root of psychostimulant-induced contextdependent sensitization, which may play a role in the development of addiction, dyskinesia, and amphetamine-induced psychosis and it occurs when dopaminergic neurons are activated, for example by rewards. As a result, neutral stimuli gain incentive salience as well as the ability to trigger future attraction or other stimulus-seeking reactions [57]. Schmidt et al. suggested that if these pathological conditions arise as a result of a gradual process of sensitization, then the therapeutic effect should follow the principle of gradual desensitization. Thus, psychostimulant-induced sensitization and dopamine-deficiency-induced behavior deterioration follow a common pathobiological mechanism that proceeds in two opposite 
directions [57]. Although dopaminergic and glutamatergic neurotransmission have long been considered to modulate sensitization, the role of GABA-ergic metabolism and its influence on mesolimbic and mesocortical pathways, whose alterations are exhibited in schizophrenia, has received more attention lately [58] (Figure 2).

Although scientists declared glutamatergic neurotransmission as a targeted strategy for the development of treatments for schizophrenia 40 years ago [59,60], the pharmaceutical industry became interested in this direction only about a decade ago [61]. Early studies examined NMDA-receptor dysfunction through the lens of the widespread dopamine hypothesis of schizophrenia [62-64], while recent research is now focusing on NMDAreceptor deficiency as a primary element in dysfunctional brain networks leading to dopamine-mediated psychosis as a consequence [65-67].

\subsubsection{Schizophrenia as a Syndrome of Impaired Functional Brain Connectivity}

The "dysconnection hypothesis" $[68,69]$ describes schizophrenia as a disorder caused by a failure of functional integration in the brain and is based on a model of functional (synaptic) connectivity, specifically an abnormal regulation of synaptic efficacy. This hypothesis states that psychosis is best understood at a systems level, in terms of abnormal synaptic efficacy that mediates the effect of intrinsic and extrinsic connections. It suggests that the interactions between NMDA receptor activity and modulatory neurotransmitter systems are the fundamental pathophysiological substrate of schizophrenia. The core molecular mechanism that prevents individuals' capacities to identify the right kinds of neuronal information for processing to generate coherent models of their world so they can understand it properly is a subtle but harmful failure of synaptic processing that mediates the functional integration or connectiveness of distributed brain processing [70].

Functional connectivity is a term that describes observable interactions between parts of the brain, but it does not specify how these connections are mediated and in what direction they interact. An effective connectivity, which is closer to the intuitive concept of connection, is utilized for a more thorough definition of the integration in the system (i.e., the influence that one neural system exhibits on another and the direction of interaction). In electrophysiology, there is a tight connection between effective connectivity and synaptic efficiency at the synaptic level [71].

Analyses of functional connectivity reveal various brain networks that represent distinct functions and diverse spatial topologies. Among the different brain networks that have been found to be malfunctioning in schizophrenia are the salience network (SN), the default mode network (DMN), and the central executive network (CEN), which together form the so-called "triple network" [72]. The SN consists of the anterior insula (AI) and the dorsal part of the anterior cingulum (dACC). By integrating sensory, emotional, and cognitive information, it engages in complex tasks including communication, social behavior, and self-awareness [73]. This network's role is to control the dynamic changes in and between other networks, and it is essential for a rapid shift of focus. DMN is composed of the precuneus (PC), posterior cingulate cortex (PCC), medial prefrontal cortex (mPFC), and lateral parietal cortex. It activates when individuals concentrate on their inner experiences, such as dreaming, predicting the future, meditating, or recalling memories. DMN function is inversely correlated to brain networks that focus on external stimuli [74-76]. When an individual focuses their attention on a task, this network becomes deactivated [77]. CEN is composed of the dorsolateral prefrontal cortex (DLPFC), the posterior parietal cortex, the medial frontal gyrus (MFG), the superior frontal gyrus (SFG), the ACC, the paracingular gyrus, the ventrolateral prefrontal cortex (VLPFC), and subcortical areas such as the thalamus. This network is involved in executive functions, as well as coping with intentional, cognitively demanding activities [78], and intellectual ability control [79]. It is typically inactivated during rest [80-82] and plays a significant role in decision-making and active attention modulation [83]. 
Impaired synchronization between the anti-correlated DMN and CEN is postulated as a key pathophysiological feature of schizophrenia [84]. The "triple network" is presented in Figure 3.

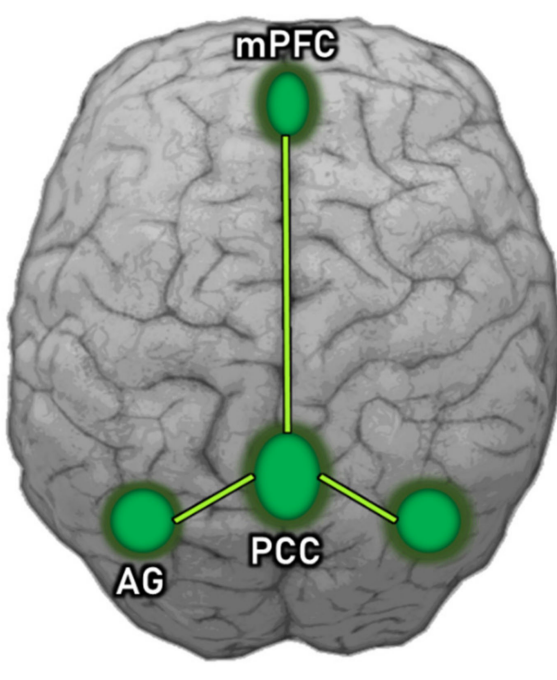

(a)

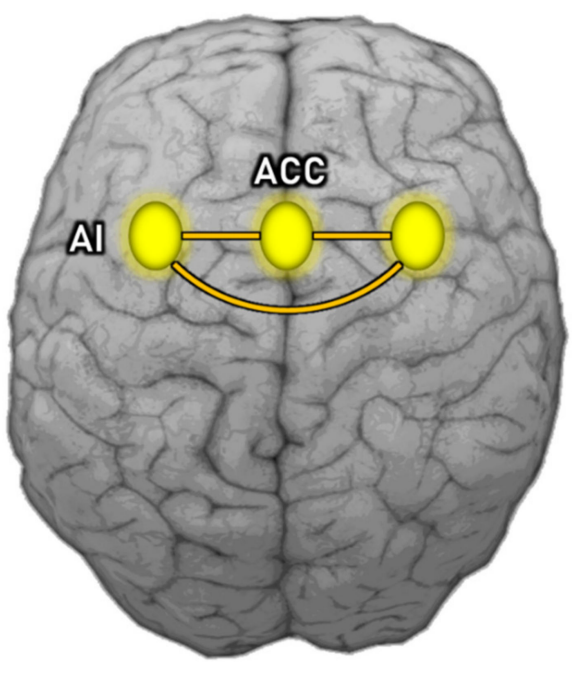

(b)

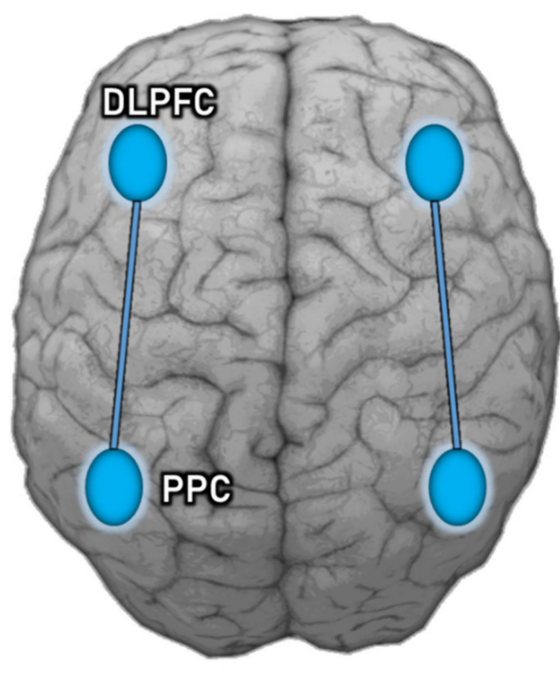

(c)

Figure 3. "Triple network": (a) Default mode network; (b) Salience network; (c) Central executive network. AG—Angular gyrus; mPFC - medial prefrontal cortex; PCC—Posterior cingulate cortex; AI-Anterior insula; ACC-Anterior cingulate cortex; DLPFC—Dorsolateral prefrontal cortex; PPC—Posterior parietal cortex.

Table 1 presents the etiological hypotheses for schizophrenia, as well as some of the significant findings in support of each hypothesis. 
Table 1. Etiological frameworks of psychosis.

\begin{tabular}{|c|c|c|c|}
\hline Concept & Definition & Studies & Main Findings/Conclusion \\
\hline \multirow{5}{*}{$\begin{array}{l}\text { Dopamine } \\
\text { hypothesis }\end{array}$} & \multirow{5}{*}{$\begin{array}{l}\text { Hyperdopaminergia in the mesolimbic system causes } \\
\text { psychotic symptoms and hypodopaminergia in the } \\
\text { mesocortical pathway is the reason for negative } \\
\text { symptoms. }\end{array}$} & Seeman and Lee (1975) [36] & Neuroleptics' efficacy in blocking dopamine D2 receptors. \\
\hline & & Lieberman et al. (1987) [37] & Psychotic phenomena are triggered by the dopamine agonists. \\
\hline & & $\begin{array}{l}\text { Breier et al. (1997) [38] } \\
\text { Laruelle et al. (1999) [39] } \\
\text { Abi-Dargham et al. (1998) [40] } \\
\text { Kegeles et al. (2000) [41] }\end{array}$ & $\begin{array}{l}\text { Amphetamine-induced hyperdopaminergia in the striatum is } \\
\text { significantly higher in patients with schizophrenia compared to healthy } \\
\text { controls. }\end{array}$ \\
\hline & & Gibbs (1951) [42] & $\begin{array}{l}\text { Epileptic seizures caused by lesions in the limbic regions lead to florid } \\
\text { psychotic production. }\end{array}$ \\
\hline & & Malamud (1967) [43] & Tumors in the limbic structures cause psychotic symptoms. \\
\hline \multirow{7}{*}{$\begin{array}{l}\text { Glutamate } \\
\text { hypothesis }\end{array}$} & \multirow{7}{*}{$\begin{array}{l}\text { A decrease of glutamate activity at the glutamate } \\
\text { synapse, particularly in the prefrontal cortex induces } \\
\text { positive, negative, and cognitive symptoms that are } \\
\text { virtually indistinguishable from those seen in } \\
\text { schizophrenia. }\end{array}$} & Kegeles et al. (2000) [41] & $\begin{array}{l}\text { Amphetamine-induced hyperdopaminergic activity in schizophrenia } \\
\text { result from disturbances in the glutamatergic neuronal systems that } \\
\text { regulate dopaminergic cellular activity. }\end{array}$ \\
\hline & & $\begin{array}{l}\text { Lahti et al. (1995) [46] } \\
\text { Kapur et Seeman (2002) [47] } \\
\text { Frohlich and Van Horn (2014) [48] } \\
\text { Javitt (2002) [49] }\end{array}$ & $\begin{array}{l}\text { Phencyclidine and ketamine which are dissociative anesthetics act as } \\
\text { glutamate antagonists by blocking the glutamate receptor of the } \\
N \text {-methyl- } D \text {-aspartate (NMDA) type and induce positive, negative, and } \\
\text { cognitive symptoms. }\end{array}$ \\
\hline & & $\begin{array}{l}\text { Olney and Farber (1995) [50] } \\
\text { Grace (1991) [51] }\end{array}$ & $\begin{array}{l}\text { Impaired dopaminergic neurotransmission in schizophrenia may itself } \\
\text { be secondary to the abnormal NMDA-receptor neurotransmission. }\end{array}$ \\
\hline & & $\begin{array}{l}\text { Goldman-Rakic and Selemon (1997) [52] } \\
\text { Weinberger and Berman (1996) [53] } \\
\text { Du et al. (2019) [54] } \\
\text { Walton et al. (2018) [55] }\end{array}$ & $\begin{array}{l}\text { Abnormalities of glutamatergic afferent neurons from the prefrontal } \\
\text { cortex to the dopaminergic subcortical areas of the midbrain are } \\
\text { associated with abnormal dopamine regulation. }\end{array}$ \\
\hline & & $\begin{array}{l}\text { Coyle (1996) [66] } \\
\text { Lisman et al. (2008) [67] }\end{array}$ & $\begin{array}{l}\text { NMDA-receptor deficiency may be the primary element in a } \\
\text { dysfunctional brain network leading to dopamine-mediated psychosis in } \\
\text { consequence. }\end{array}$ \\
\hline & & Stone et al. (2007) [85] & $\begin{array}{l}\text { Ketamine anesthesia does not cause psychotic symptoms in prepubertal } \\
\text { children when compared to anesthesia in adults (onset of schizophrenia } \\
\text { in early adulthood). }\end{array}$ \\
\hline & & Olney et al. (1999) [86] & $\begin{array}{l}\text { A chain of neural connections involved in processes generating psychotic } \\
\text { phenomena and neurotoxicity result from NMDA-receptor antagonism, } \\
\text { and this chain does not fully develop until the end of adolescence (onset } \\
\text { of schizophrenia). }\end{array}$ \\
\hline
\end{tabular}


Table 1. Cont.

Concept

\section{Main Findings/Conclusion}

Incentive learning is thought to underpin psychostimulant-induced context-dependent sensitization, which may be important in the development of addiction, dyskinesia, and amphetamine-induced psychosis.

Schizophrenia can be described as impaired Schmidt and Beninger (2006) [57]

Dysconnection hypothesis integration in the brain and is based on a model of

functional (synaptic) connectivity, specifically an

abnormal regulation of synaptic efficacy.

The "triple network" system is malfunctioning in schizophrenia.

Impaired synchronization between the anti-correlated Default mode network and Central executive network is a key pathophysiological feature of schizophrenia. 


\subsubsection{An Integral Etiological Framework for Schizophrenia}

The concept that schizophrenia represents disintegration or fragmentation of the mind is as ancient as the term "schizophrenia" itself, which was coined by Bleuler [87] to highlight the "splitting" of the mind. Many of the fundamental symptoms (A-symptoms) presented by Bleuler, such as "associative disorganization," emphasize the fragmentation and the lack of a continuous integration of the cognitive process. The nature of this integration (functional integration) at the neuronal level is an essential component in theoretical neurobiology [71].

The typical onset of schizophrenia in the transition phase between late adolescence and early adulthood is one of its main characteristics. Studies with rats demonstrate that ketamine and PCP are not neurotoxic until late adolescence. Furthermore, human investigations have shown that ketamine anesthesia does not cause psychotic symptoms in prepubertal children when compared to anesthesia in adults [85]. Olney et al. [86] suggest that this is due to a chain of neural connections involved in processes generating psychotic phenomena and neurotoxicity that result from NMDA-receptor antagonism, and this chain does not fully develop until the end of adolescence. According to Olney and Farber [50], impairment in the functioning of NMDA receptors (or the cells on which they are expressed) exists from the early stages of development, but the onset of psychotic symptoms occurs only after the full development of neural connections in early adulthood. This model supports the neurodevelopmental theory for schizophrenia, which speculates that brain abnormalities occur early in life, but remain dormant until late adolescence, when the pruning of neural connections occurs [88,89].

It has been suggested that glutamate may serve as a "bridge" uniting neurodevelopment and neurodegenerative theories due to its active participation in neuronal processes during all periods of human development. In early development, glutamate plays a role in neural migration, in adolescence it plays a role in the plasticity and pruning of neurons, and later in life, it is involved in neurodegeneration through the process of excitotoxicity [90].

Neurotransmitters tend to alter the excitability of neurons not only by directly affecting the postsynaptic membrane potential but also through modifying their responsiveness to other neurotransmitters. In the PFC, for example, dopaminergic terminal axons contribute to the development of synaptic complexes including excitatory (glutamatergic) projections on the pyramidal cells [91]. This synaptic arrangement represents the interplay of dopamine and glutamate neurotransmission, both of which are involved in modulating cortical connectivity. The brain connectivity is in a constant state of flow, where the neuronal dynamics influence the neuronal processes and the synaptic specializations. Therefore, connectivity is constantly changing (especially during growth). Brain plasticity (e.g., associative plasticity, self-organization, activity-dependent changes in synaptic efficacy, or experimentally induced long-term potentiation) combines processes such as brain connectivity and neuronal dynamics (i.e., interconnection). This is important because the "dysplastic" theories of schizophrenia and the theories of "impaired brain connectivity" are essentially the same and by default, both point to the hypothesis of impaired neurodevelopment.

In summary, schizophrenia can be considered as a mental disorder of impaired brain connectivity, the course of which is modeled by complex etiopathogenic factors, and at each stage of development, certain abnormal neurobiological processes contribute to its clinical manifestation. These processes originate from a genetic predisposition embedded in the genome, which is a prerequisite for the further development of the disease [92].

Later, during early development, the abnormalities stay dormant, followed by the prodromal phase, during which neuronal maturation occurs, then, due to endogenous neurochemical dysfunction and environmental factors, the full clinical manifestation of the disease occurs, reaching the residual phases of schizophrenia, during which neurodegenerative disorders predominate [93].

The integral model of schizophrenia is presented in Figure 4. 


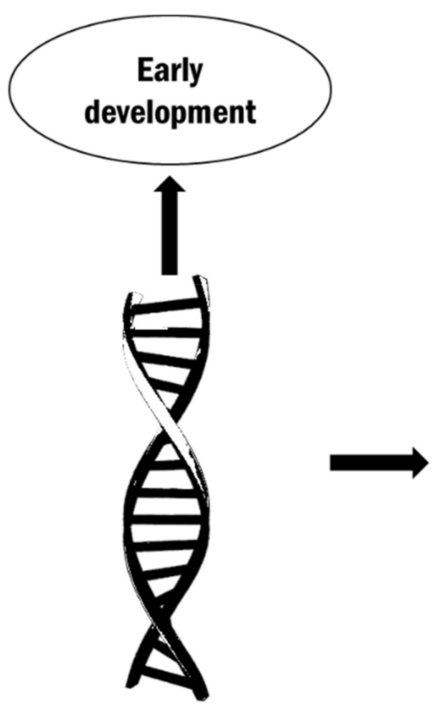

Genetic predisposition

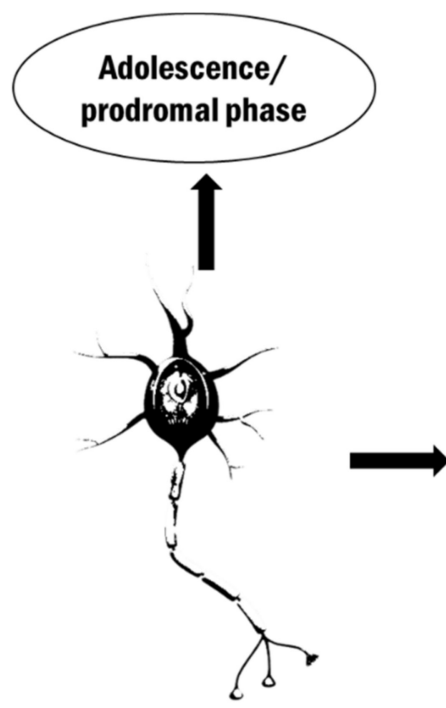

Neuronal maturation

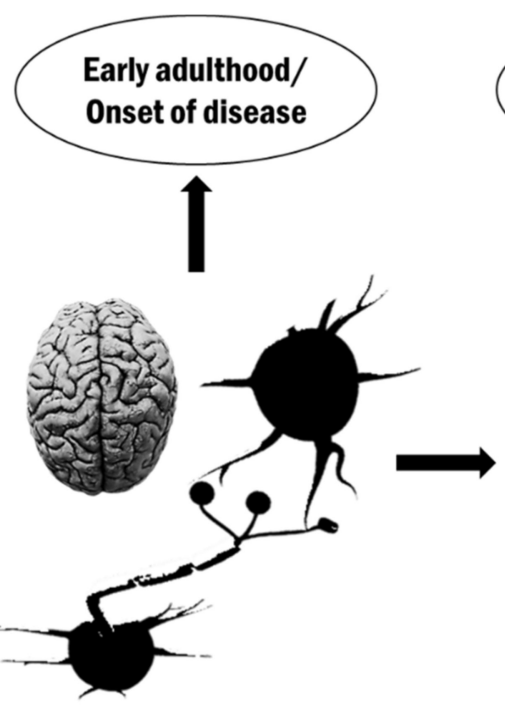

Abnormal neurotransmission \& aberrant connectivity
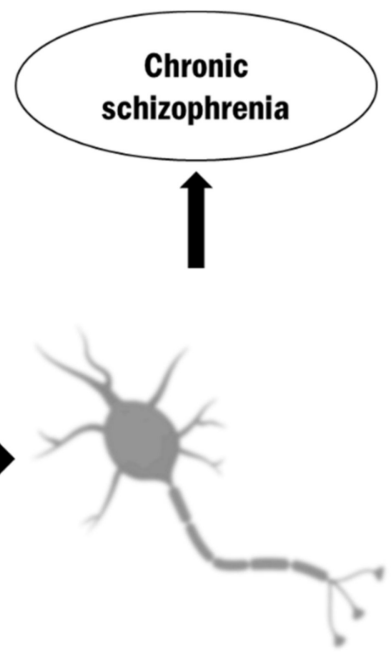

Excitotoxicity

Figure 4. Integral etiological model of schizophrenia.

\subsection{The Role of Neuroimaging and Translational Neuroscience in Schizophrenia Research}

Understanding the complex dynamics of interactions between different brain areas at rest and during conditional task performance is a relevant subject in research about the underlying pathophysiological mechanisms of psychotic disorders. Disruptions in communication between and within brain networks, and the pathophysiological processes of their nodes enable translational neuroscience to obtain biological insight into schizophrenia and to describe it as impaired connectivity disorder [94].

A wide range of scientific fields and new methodologies are part of the translational approach in psychiatry. Magnetic resonance imaging (MRI) such as quantitative structural imaging, voxel-based neuromorphometry (VBM), functional neuroimaging, and spectroscopy are commonly used in research. Structural and functional MRI has the potential to refine diagnoses, assist in making therapeutic decisions, and be incorporated as a method of monitoring the effect of treatment by directly assessing the improvement of disease-related brain dysfunction. The different imaging modalities report diverse and specific CNS impairments, some of which will be presented in the following lines.

Table 2 presents important findings for schizophrenia, established by different modalities of magnetic resonance imaging. 
Table 2. Magnetic resonance imaging findings in schizophrenia research.

\section{Magnetic-Resonance Imaging Technique}

\section{Study}

Zhuo et al. (2017) [95]

van Erp et al. (2016) [96]

Chang et al. (2016) [97]

Structural neuroimaging

Stoyanov et al. (2021) [99]

Shepherd et al. (2012) [100]

Goodkind et al. (2015) [101]

Sheffield et al. (2020) [102]

Lee et al. (2016) [103]

Mier et al. (2014) [104]

Mier et al. (2014) [104]

Goghari et al. (2017) [105]

Belge et al. (2017) [106]

Functional task-related neuroimaging

Whitfield-Gabrieli et al. (2009) [107]

Stoyanov et al. (2021) [108]

Nekovarova et al. (2014) [109]

Functional resting-state neuroimaging

Zhou et al. (2016) [110]

Stoyanov et al. (2021) [108

Aryutova et al. (2021) [111]

\section{Main Findings/Conclusion}

Schizophrenic patients have reduced gray matter volumes in the frontal, temporal, and parietal areas, the cingulate gyrus, and limbic structures (hippocampus, parahippocampus and thalamus).

Decrease in the amygdala and increase in the pallidum, which is directly associated to the longevity of the disorder which can be interpreted as evidence in favor of the neurodegenerative hypothesis of schizophrenia.

Reduction in grey matter volumes in the vermis, superior temporal gyrus, operculum. Elevated cerebro-spinal fluid volume.

Regions located in the left and right opercular part of inferior frontal gyrus, right supramarginal gyrus, left superior temporal gyrus, left anterior orbital gyrus, supplementary motor cortex, and several occipital areas are highly discriminatory for convergent cross-validation of biological features of psychosis vs. depression.

Grey matter volume of the bilateral insula is reduced in psychotic disorders, and a progressive structural decrease is recorded throughout the course and chronicity of the progressive st
condition.

Reduced accuracy in recognizing emotions and prolonged response time in patients with schizophrenia.

Task-related hyperactivation in the components of the Default mode network psychotic in patients, while in healthy controls-deactivation in the same network.

Activations in Default mode network components during cognitive processing of paranoid-specific items from the von Zerssen's Paranoid-depressive scale [108].

Impaired coordination of Default mode network / Central executive network / Salience network is associated with disorientation between internally and externally focused attention and cognitive impairment.

Reduced task-related Default mode network suppression is a psychosis-specific biomarker for cognitive impairment, as the finding is established only in psychotic individuals with cognitive decline.

There is a strong aberrant brain connectivity in schizophrenia-an inhibitory influence from prefrontal cortex to Salience network (anterior insula) and an excitatory connection from the anterior cingulate cortex to anterior insula $[108,111]$. 
Structural MRI investigations in psychotic individuals have revealed a variety of anatomical abnormalities in the CNS. Reduced GM volumes have been detected in several brain regions, including the frontal, temporal, parietal areas, the cingulate gyrus, and limbic structures (hippocampus, parahippocampus and thalamus) [95]. According to recent findings from the ENIGMA consortium, there is a considerable decrease in the size of the amygdala and a significant increase in the pallidum, which is directly associated with the longevity of the disorder [96] and can be interpreted as evidence in favor of the neurodegenerative hypothesis of schizophrenia. Brain abnormalities are also found in patients with their first psychotic episode, mainly as a reduction in GM volumes in the vermis, STG, operculum, etc. [97]. STG is a cortical zone that belongs to the auditory cortex, and the reduction in its GM volumes is associated with auditory hallucinations [112], which are a typical schizophrenic symptom. Another persistent finding is the enlarged lateral ventricles and the elevated cerebro-spinal fluid volume [98].

A recent study performed by our research group, consisting of a multivariate analysis of different MRI modalities, using artificial intelligence (unsupervised machine learning method) comparing paranoid syndrome in schizophrenia and depressive syndrome in the context of mood disorder, found that regions located in the left and right opercular part of the inferior frontal gyrus (IFG), right supramarginal gyrus, left STG, left anterior orbital gyrus, supplementary motor cortex, and several occipital areas are highly discriminatory for convergent cross-validation of biological features of disease [99].

One of the most consistent anatomical findings in schizophrenia is the abnormal insula structure. According to meta-analyses, the GM volume of the bilateral insula is reduced, and while evident in other mental illnesses, the reduced insula volume, is most pronounced in psychotic disorders [100-102]. This observation is present even in patients experiencing their first psychotic episode [103], and a progressive structural decrease is recorded throughout the course and chronicity of the condition [113].

fMRI research results collected during the performance of various tasks (task-related fMRI) while identifying activations in different brain areas when applying various sensory stimuli constitute a large part of the data published in the literature related to neuroimaging. Numerous task-related neuroimaging studies with emotionally charged visual stimuli have demonstrated reduced accuracy in recognizing emotions and prolonged response time in patients with schizophrenia [104-106].

In addition, task-related hyperactivation in the components of the DMN is observed in psychotic patients, while in healthy controls, deactivation in the same network is reported [107].

Studies have shown that impaired coordination of DMN/CEN/SN is associated with disorientation between internally and externally focused attention and cognitive impairment, which are typical signs of psychotic disorders [109]. Impaired synchronization between DMN and CEN results in an inability of the DMN to deactivate during cognitive load [108]. Zhou et al. [110], by conducting a fMRI study on 3 target groups (individuals with first psychotic episode without cognitive deficits, individuals with first psychotic episode with cognitive decline, and healthy controls), managed to prove that reduced task-related DMN suppression is a psychosis-specific biomarker for cognitive impairment, as the finding was established only in the group of psychotic individuals with cognitive decline.

Our research team, led by Stoyanov, has developed and integrated an innovative neuroimaging paradigm [108] aimed at translational cross-validation of von Zerssen's Paranoid-Depressive Scale (PDS) [114] through its simulant implementation during functional imaging in individuals with paranoid and depressive syndrome. The obtained results confirm previous findings [107] that activations in the components of DMN in psychotic patients are completely absent among depressed patients. The novelty and distinctiveness of our design is that activations in DMN components are detected in schizophrenia patients during cognitive processing of paranoid-specific items on the scale. This discovery has a huge impact because it not only confirms prior findings from separate research, establishing 
a biomarker that is diagnostically specific for paranoid syndrome, but it also biologically validates von Zerssen's PDS.

In this sense, psychiatry acquires a psychometric tool that is evidence-based and can be freely used in clinical practice. PDS can be implemented not only for initial diagnostic assessment, but also for monitoring the progress of the disease, as well as for monitoring the therapeutic effect, as the initial establishment of this scale was precisely in order to assess the effectiveness of treatment.

fMRI at rest (resting-state fMRI) examines the complex interactions between predefined ROIs using general linear model (GLM) and dynamic causal modeling (DCM) analysis. The study of functional connectivity at rest reveals a number of neural networks that represent specific patterns of synchronous activity [83]. Resting-state fMRI is used to identify dysfunctional integration or abnormal connectivity in the brain, either between individual brain regions or in between brain networks [115].

In healthy individuals, $\mathrm{SN}$ activation is often observed throughout a variety of cognitive tasks [116]. Its major purpose is to enable brain connectivity switching between the anti-correlated default mode and task-related states [117]. The insula is a key component of $\mathrm{SN}$ that executes a wide range of cognitive and affective functions, including self-awareness, emotional response and empathy.

Studies conducted by our team on resting-state effective connectivity prove an aberrant brain connectivity in schizophrenia $[108,111]$, i.e., an inhibitory influence from PFC to Salience network (anterior insula) and an excitatory connection from the dACC to AI (hyperconnectivity of $\mathrm{SN}$ ).

We suggest that the observed task-related hyperactivity of the DMN may be a consequence of the inhibition from the PFC on the insula, which disrupts its balancing function as a dynamic switch between the anti-correlated DMN and CEN.

In addition, the SN hyperconnectivity points to the conclusion that schizophrenic patients stay in a "resting-state of aberrant salience", instead of a "resting-state of default mode". Such a conceptual model helps understanding of schizophrenia as a behavioral disorder caused by disintegration in key brain networks. Abnormal SN hyperconnectivity and fronto-insular inhibition at rest prevent $\mathrm{SN}$ function from acting as a dynamic switch between resting-state (DMN) and event-related (CEN) activity. The fundamental disruption of SN in schizophrenia prevents switching between anti-correlated DMN and CEN, thus interfering with their basic functions.

This concept is presented in Figure 5. 

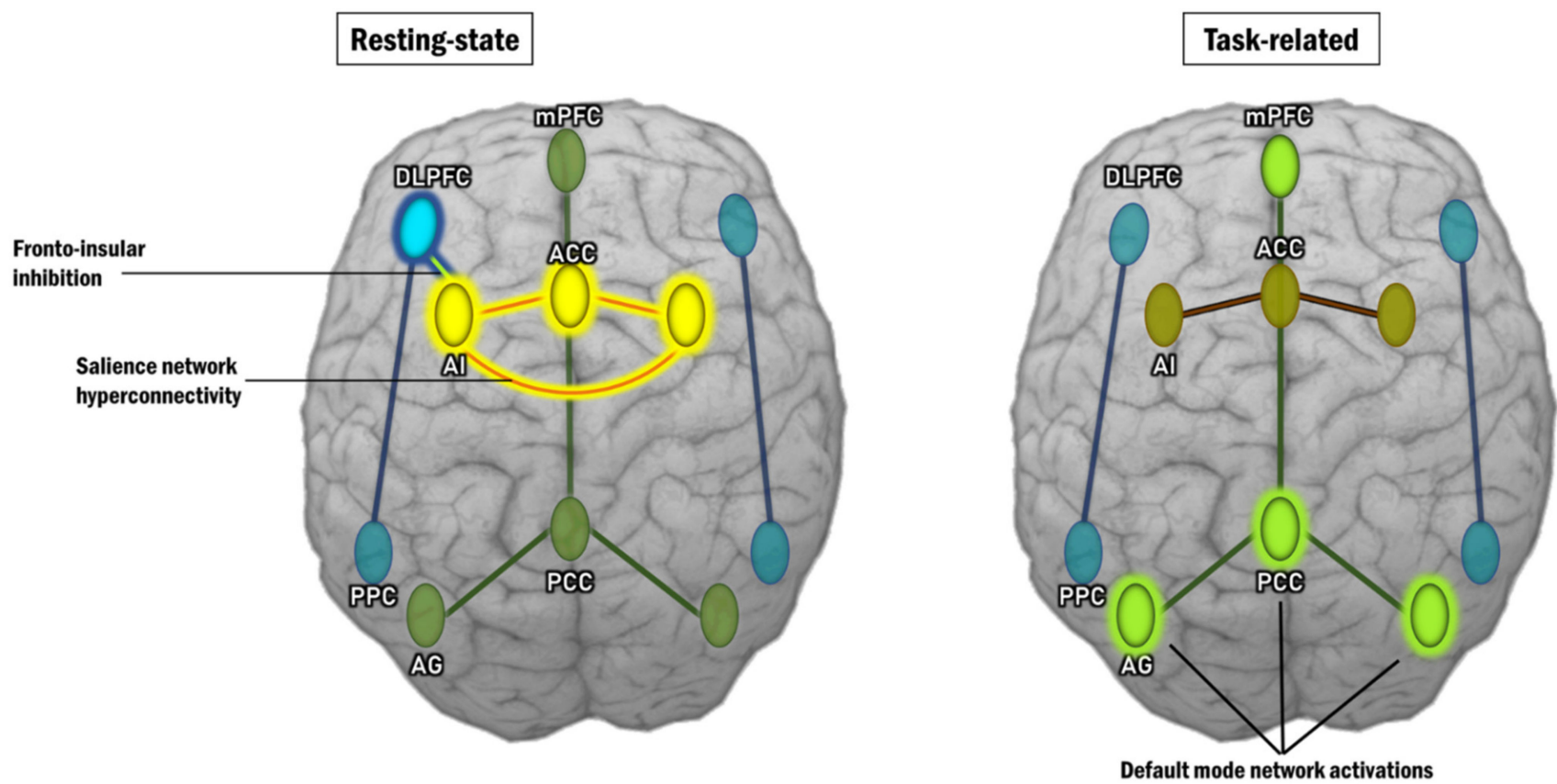

Figure 5. Resting-state aberrant connectivity and task-related abnormal activations that are observed in schizophrenic patients. AG-Angular gyrus; mPFC-Medial prefrontal cortex; PCC-Posterior cingulate cortex; AI-Anterior insula; ACC_-Anterior cingulate cortex; DLPFC—Dorsolateral prefrontal cortex; PPC—Posterior parietal cortex.

\subsection{Implications of Neuroimaging Findings for the Treatment of Schizophrenia}

Given the controversial efficacy of standard therapies (psychopharmacology and psychotherapy), a significant proportion of schizophrenic patients do not achieve full remission (i.e., become asymptomatic) or maintain symptom relief. This lack of efficacy has prompted the search for alternate treatments, which include the use of more invasive procedures for treatment-resistant cases of schizophrenia [118]. As a result, the focus has shifted to methods for neuromodulation or modification of connections between different pathways and neurotransmitter systems in the brain. This interest is motivated by the improved neurobiological views of the origin of psychosis and the neuroimaging findings, which have led to the ability to regulate the central disruptions through direct and focal modulation of brain activity [94].

Unconventional therapeutic instrumental methods have been shown to be beneficial for a variety of psychiatric disorders (e.g., electro-convulsive therapy for depression, mania, and catatonia; transcranial magnetic stimulation for treatment-resistant depression; transcranial direct current stimulation for cognitive deficiency in schizophrenia; deep brain stimulation for obsessive-compulsive disorder, addiction, and severe forms of depression). Unfortunately, their usage for schizophrenia is still limited in standard clinical protocols, and these technologies remain in the shadow of psychopharmacology [94].

However, we remain positive about the possibilities for improving the therapeutic approach to psychosis, as some of the modern neuroimaging techniques can provide available resources for non-invasive analysis of complex interactions and biochemical imbalances that cause the characteristic manifestation of the disease. The study of the pharmacokinetic and pharmaco-dynamic processes occurring in the CNS under the load of various chemicals could help both to identify psychosis-specific biomarkers and to develop an effective strategy for monitoring and predicting the effect of drug treatment.

\section{Discussion}

One of the most essential elements of comprehending inter-individual differences or clinical results is to investigate the neurochemical substrates of brain function. Positron emission tomography (PET) has allowed for a direct assessment of brain chemistry in vivo. 
The dynamics of regional uptake of neurotransmitter-specific radio-ligands in PET can be used to identify regional neurochemical modulation of brain activity. PET mostly uses 18FDG, a direct reflection of regional glutamate transmission, to offer a quantifiable measure of glucose metabolism [119]. PET is considered as a "gold standard" for identification of chemical imbalances in the brain and has been investigating for a long time the neural correlates of psychiatric conditions like exogenous psychosis caused by ketamine $[120,121]$, depression [122,123] and euphoric intoxication [124]. The downfall of PET is that it is an expensive tool that operates with specific ligands, and it is not appropriate for repeated research due to the dose-radiation restrictions protocols, with some Ethics commissions completely forbidding it in healthy individuals. Furthermore, it can capture a single "snapshot" binding to a receptor molecule, within the limited time between administration and semi-elimination of the radio-ligand.

Therefore, the focus is on pharmacological MRI (ph-MRI), which is an accessible instrument as an alternative for studying the chemical imbalances in the brain. ph-MRI is an innovative technology for assessing regional network effects and treatment response to specific medications. In general, there are two types of ph-MRI. The first is usually done as a drug challenge study, in which MRI signal changes are evaluated after an acute administration of the substance of interest. Apparently, there are several adaptations on this fundamental paradigm, such as drug antagonistic effects or investigating the acute effects of one medication on the chronic effects of another (useful perhaps for studying drug addictions). The second type of ph-MRI is the observation of pharmaco-modulatory effects of drugs on a traditional task-related fMRI study, such as dopaminergic medicines' effects on cognitive tasks [125].

The main purpose of phMRI is to recognize the location of drug action fingerprinting in order to measure the connection between drug dose, neural reaction, and treatment significance over time (pharmacokinetic/pharmacodynamic modeling), and to assist in making go-nogo decisions about the efficacy of drug treatment in clinical trials, all with the goal of accelerating drug discovery. By enabling a controlled regulation of a specific pathway and analyzing its causal influence on other signals and systems, pharmacological probing tests can be useful for fundamental neuroscience and validation studies [119].

The dopamine and glutamate neurotransmitter systems are the main targets for phMRI in schizophrenia. Suitable ligands for examining the dopamine system are cocaine, amphetamine, and L-DOPA, while ketamine, phencyclidine (PCP), and LY2140023 are appropriate substances for studying the glutamate systems [125]. The main advantage of ph-MRI is that it can investigate the effects of pharmacological agents at the network level and remotely from areas of high target receptor densities, whereas PET and molecular studies can define target receptor occupancy and affinity without necessarily translating effects to large-scale networks [126]. As a result, ph-MRI provides a "system evaluation" of networks underpinning a drug's behavioral effects, irrespective of its pharmacological mechanism of action [127]. Because functional MRI can monitor the cumulative effect of these interactions across many brain areas, ph-MRI has the potential to generate "mechanism-related activation maps" that may be used as targets for drug testing [128].

Given the intricacy of the clinical presentation and the underlying malfunctioning brain circuits, ph-MRI investigations can assist in determining the initial treatment response, mechanisms of therapeutic efficacy and adverse effects, and potentially accelerate CNS drug development. ph-MRI studies reveal stable and reproducible alterations on diseaserelevant networks, as well as sensitivity to early pharmacological impacts on diseaserelated functional architecture. Improved disease phenotyping, or biomarkers, utilizing sophisticated imaging techniques will substantially assist future CNS medication research and development.

\section{Conclusions}

Schizophrenia and other psychotic disorders affect a huge number of people around the world, thus destroying the lives of patients, burdening their loved ones and soci- 
ety, and leading to significant and global economic losses. Theories about the origin of schizophrenia have changed over the years, starting with the supernatural, going through the psychodynamic "schizophrenogenic mother" and reaching modern interpretations of the etiology of this destructive disease. For more than half a century, neurobiology has been able to provide explanations for the central brain mechanisms of the disease through the neurodevelopment hypothesis, the neurodegeneration hypothesis, and the biochemical dysfunction represented by the dopamine and glutamate hypotheses. In recent decades, thanks to neuroimaging, new insights have been gained about the disrupted integration in communication between and within the brain networks, emphasizing the disrupted connectivity between the components of the triple network, the default mode network, salience network and central executive network, which form the concept of schizophrenia as a brain dysconnectivity syndrome. At this stage, neuroscience has the task of combining different concepts into an integral model with the clear goal of contributing to the development of new treatments for schizophrenia. A suitable tool for this is pharmacological magnetic resonance imaging which has the ability to measure the connection between drug dose, neural reaction, and treatment significance over time, thus providing a "system evaluation" of networks underpinning a drug's behavioral effects, irrespective of its pharmacological mechanism of action.

According to the validation theory as conceived back in 2007, the cross-validation of clinical psychological self-assessment tools with fMRI may well underpin pharmacopsychological monitoring strategies [129].

Advances in neuroscience are expected to provide new horizons in the near future by incorporating neuroimaging findings into clinical practice, including non-traditional neuromodulation methods in the therapeutic approach of schizophrenia.

Author Contributions: Conceptualization, K.A. and D.S.; writing-original draft preparation, K.A.; writing-review and editing, D.S.; visualization, K.A.; supervision, D.S.; project administration, D.S. Both authors have read and agreed to the published version of the manuscript.

Funding: This research received no external funding.

Conflicts of Interest: The authors declare no conflict of interest.

\section{References}

1. Gaebel, W.; Zielasek, J. Focus on psychosis. Dialog. Clin. Neurosci. 2015, 17, 9-18.

2. Rössler, W.; Salize, H.J.; van Os, J.; Riecher-Rössler, A. Size of burden of schizophrenia and psychotic disorders. Eur. Neuropsychopharmacol. 2005, 15, 399-409. [CrossRef]

3. Joyce, E.M.; Roiser, J. Cognitive heterogeneity in schizophrenia. Curr. Opin. Psychiatry 2007, 20, 268-272. [CrossRef]

4. Owen, M.J.; Sawa, A.; Mortensen, P.B. Schizophrenia. Lancet 2016, 388, 86-97. [CrossRef]

5. Addington, J.; Heinssen, R. Prediction and Prevention of Psychosis in Youth at Clinical High Risk. Annu. Rev. Clin. Psychol. 2012, 8, 269-289. [CrossRef]

6. Freudenreich, O. Differential Diagnosis of Psychotic Symptoms: Medical “Mimics". Psychiatr. Times 2010, $27,56-61$.

7. American Psychiatric Association. Diagnostic and Statistical Manual of Mental Disorders (DSM-5®); American Psychiatric Association Publishing: Washington, DC, USA, 2013.

8. World Health Organization. The ICD-10 Classification of Mental and Behavioural Disorders: Clinical Descriptions and Diagnostic Guidelines; World Health Organization: Geneva, Switzerland, 1992.

9. Jakobsen, K.D.; Frederiksen, J.N.; Hansen, T.F.; Jansson, L.B.; Parnas, J.; Werge, T. Reliability of clinical ICD-10 schizophrenia diagnoses. Nord. J. Psychiatry 2005, 59, 209-212. [CrossRef]

10. Brunoni, A.R. Beyond the DSM: Trends in psychiatry diagnoses. Rev. Psiquiatr. Clin. 2017, 44, 154-158. [CrossRef]

11. Trossbach, S.V.; Hecher, L.; Schafflick, D.; Deenen, R.; Popa, O.; Lautwein, T.; Tschirner, S.; Köhrer, K.; Fehsel, K.; Papazova, I.; et al. Dysregulation of a specific immune-related network of genes biologically defines a subset of schizophrenia. Transl. Psychiatry 2019, 9, 1-16. [CrossRef] [PubMed]

12. Stoyanov, D.S. An Essay on the Mind-Brain Problem and Legal Proof. Balk. J. Philos. 2018, 10, 27-36. [CrossRef]

13. Brewer, L. General Psychology: Required Reading; Deiner Education Fund: Salt Lake City, CT, USA, $2019 ;$ p. 323.

14. Bender, L. Childhood schizophrenia: Clinical study of one hundred schizophrenic children. Am. J. Orthopsychiatry 1947, 17, 40-56. [CrossRef] [PubMed]

15. Sørensen, H.J.; Mortensen, E.L.; Schiffman, J.; Reinisch, J.M.; Maeda, J.; Mednick, S.A. Early developmental milestones and risk of schizophrenia: A 45-year follow-up of the Copenhagen Perinatal Cohort. Schizophr. Res. 2010, 118, 41-47. [CrossRef] [PubMed] 
16. Rosso, I.M.; Bearden, C.; Hollister, J.M.; Gasperoni, T.L.; Sanchez, L.E.; Hadley, T.; Cannon, T.D. Childhood Neuromotor Dysfunction in Schizophrenia Patients and Their Unaffected Siblings: A Prospective Cohort Study. Schizophr. Bull. 2000, 26, 367-378. [CrossRef]

17. Jones, P. Child developmental risk factors for adult schizophrenia in the British 1946 birth cohort. Lancet 1994, $344,1398-1402$. [CrossRef]

18. Ollendick, T.H.; Prinz, R.J. (Eds.) Advances in Clinical Child Psychology; Springer US: New York, NY, USA, $1996 ;$ Volume 18.

19. Ridler, K.; Veijola, J.M.; Tanskanen, P.; Miettunen, J.; Chitnis, X.; Suckling, J.; Murray, G.; Haapea, M.; Jones, P.B.; Isohanni, M.K.; et al. Fronto-cerebellar systems are associated with infant motor and adult executive functions in healthy adults but not in schizophrenia. Proc. Natl. Acad. Sci. USA 2006, 103, 15651-15656. [CrossRef] [PubMed]

20. Taanila, A.; Murray, G.; Jokelainen, J.; Isohanni, M.; Rantakallio, P. Infant developmental milestones: A 31-year follow-up. Dev. Med. Child Neurol. 2005, 47, 581. [CrossRef]

21. Kremen, W.S.; Vinogradov, S.; Poole, J.H.; Schaefer, C.A.; Deicken, R.F.; Factor-Litvak, P.; Brown, A.S. Cognitive decline in schizophrenia from childhood to midlife: A 33-year longitudinal birth cohort study. Schizophr. Res. 2010, 118, 1-5. [CrossRef]

22. Cannon, M.; Moffitt, T.E.; Caspi, A.; Murray, R.M.; Harrington, H.; Poulton, R. Neuropsychological performance at the age of 13 years and adult schizophreniform disorder: Prospective birth cohort study. Br. J. Psychiatry 2006, 189, 463-464. [CrossRef]

23. Caspi, A.; Reichenberg, A.; Weiser, M.; Rabinowitz, J.; Kaplan, Z.; Knobler, H.; Davidson-Sagi, N.; Davidson, M. Cognitive performance in schizophrenia patients assessed before and following the first psychotic episode. Schizophr. Res. 2003, 65, 87-94. [CrossRef]

24. Kobayashi, H.; Isohanni, M.; Jääskeläinen, E.; Miettunen, J.; Veijola, J.; Haapea, M.; Järvelin, M.-R.; Jones, P.B.; Murray, G.K. Linking the developmental and degenerative theories of schizophrenia: Association between infant development and adult cognitive decline. Schizophr. Bull. 2014, 40, 1319-1327. [CrossRef] [PubMed]

25. Hulshoff Pol, H.E.; Kahn, R.S. What Happens After the First Episode? A Review of Progressive Brain Changes in Chronically Ill Patients with Schizophrenia. Schizophr. Bull. 2008, 34, 354-366. [CrossRef] [PubMed]

26. Olabi, B.; Ellison-Wright, I.; McIntosh, A.; Wood, S.; Bullmore, E.; Lawrie, S. Are There Progressive Brain Changes in Schizophrenia? A Meta-Analysis of Structural Magnetic Resonance Imaging Studies. Biol. Psychiatry 2011, 70, 88-96. [CrossRef]

27. Kempton, M.J.; Stahl, D.; Williams, S.; DeLisi, L.E. Progressive lateral ventricular enlargement in schizophrenia: A meta-analysis of longitudinal MRI studies. Schizophr. Res. 2010, 120, 54-62. [CrossRef]

28. Lieberman, J.A. Is schizophrenia a neurodegenerative disorder? a clinical and neurobiological perspective. Biol. Psychiatry 1999, 46, 729-739. [CrossRef]

29. Lin, Y.; Li, M.; Zhou, Y.; Deng, W.; Ma, X.; Wang, Q.; Guo, W.; Li, Y.; Jiang, L.; Hu, X.; et al. Age-Related Reduction in Cortical Thickness in First-Episode Treatment-Naïve Patients with Schizophrenia. Neurosci. Bull. 2019, 35, 688-696. [CrossRef]

30. Walker, E.F.; Lewine, R.R.; Neumann, C. Childhood behavioral characteristics and adult brain morphology in schizophrenia. Schizophr. Res. 1996, 22, 93-101. [CrossRef]

31. Seeman, P. Dopamine receptors and the dopamine hypothesis of schizophrenia. Synapse 1987, 1, 133-152. [CrossRef]

32. Harrington, A. The fall of the schizophrenogenic mother. Lancet 2012, 379, 1292-1293. [CrossRef]

33. Johnston, J. The Ghost of the Schizophrenogenic Mother. Virtual Mentor 2013, 15, 801-805. [CrossRef]

34. Meltzer, H.Y.; Stahl, S.M. The Dopamine Hypothesis of Schizophrenia: A Review. Schizophr. Bull. 1976, 2, 19-76. [CrossRef] [PubMed]

35. Carlsson, A.; Lindqvist, M. Effect of chlorpromazine or haloperidol on formation of 3methoxytyramine and normetanephrine in mouse brain. Acta Pharmacol. Toxicol. 1963, 20, 140-144. [CrossRef]

36. Seeman, P.; Lee, T. Antipsychotic drugs: Direct correlation between clinical potency and presynaptic action on dopamine neurons. Science 1975, 188, 1217-1219. [CrossRef] [PubMed]

37. Lieberman, J.A.; Kane, J.M.; Alvir, J. Provocative tests with psychostimulant drugs in schizophrenia. Psychopharmacology 1987, 91, 415-433. [CrossRef] [PubMed]

38. Breier, A.; Su, T.-P.; Saunders, R.; Carson, R.E.; Kolachana, B.S.; de Bartolomeis, A.; Weinberger, D.R.; Weisenfeld, N.; Malhotra, A.K.; Eckelman, W.C.; et al. Schizophrenia is associated with elevated amphetamine-induced synaptic dopamine concentrations: Evidence from a novel positron emission tomography method. Proc. Natl. Acad. Sci. USA 1997, 94, 2569-2574. [CrossRef] [PubMed]

39. Laruelle, M.; Abi-Dargham, A. Dopamine as the wind of the psychotic fire: New evidence from brain imaging studies. J. Psychopharmacol. 1999, 13, 358-371. [CrossRef]

40. Abi-Dargham, A.; Gil, R.; Krystal, J.; Baldwin, R.M.; Seibyl, J.P.; Bowers, M.; Van Dyck, C.H.; Charney, D.S.; Innis, R.B.; Laruelle, M. Increased striatal dopamine transmission in schizophrenia: Confirmation in a second cohort. Am. J. Psychiatry 1998, 155, 761-767. [CrossRef] [PubMed]

41. Kegeles, L.S.; Abi-Dargham, A.; Zea-Ponce, Y.; Rodenhiser-Hill, J.; Mann, J.; Van Heertum, R.L.; Cooper, T.B.; Carlsson, A.; Laruelle, M. Modulation of amphetamine-induced striatal dopamine release by ketamine in humans: Implications for schizophrenia. Biol. Psychiatry 2000, 48, 627-640. [CrossRef]

42. Gibbs, F.A. Ictal and non-ictal psychiatric disorders in temporal lobe epilepsy. J. Nerv. Ment. Dis. 1951, 113, 522-528.

43. Malamud, N. Psychiatric Disorder With Intracranial Tumors of Limbic System. Arch. Neurol. 1967, 17, 113-123. [CrossRef] [PubMed] 
44. Kantrowitz, J.T.; Javitt, D.C. Tinking Glutamatergically: Changing Concepts of Schizophrenia Based Upon Changing Neurochemical Models. Clin. Schizophr. Relat. Psychoses 2010, 4, 189-200. [CrossRef]

45. Yang, A.C.; Tsai, S.-J. New Targets for Schizophrenia Treatment beyond the Dopamine Hypothesis. Int. J. Mol. Sci. 2017, 18, 1689. [CrossRef]

46. Lahti, A.C.; Koffel, B.; LaPorte, D.; Tamminga, C.A. Subanesthetic doses of ketamine stimulate psychosis in schizophrenia. Neuropsychopharmacology 1995, 13, 9-19. [CrossRef]

47. Kapur, S.; Seeman, P. NMDA receptor antagonists ketamine and PCP have direct effects on the dopamine D2 and serotonin 5-HT2 receptors-Implications for models of schizophrenia. Mol. Psychiatry 2002, 7, 837-844. [CrossRef] [PubMed]

48. Frohlich, J.; Van Horn, J.D. Reviewing the ketamine model for schizophrenia. J. Psychopharmacol. 2014, 28, 287-302. [CrossRef] [PubMed]

49. Javitt, D.C. Glutamate and Schizophrenia: Phencyclidine, N-Methyl-d-Aspartate Receptors, and Dopamine-Glutamate Interactions. Int. Rev. Neurobiol. 2007, 78, 69-108. [CrossRef] [PubMed]

50. Olney, J.W.; Farber, N.B. Glutamate receptor dysfunction and schizophrenia. Arch. Gen. Psychiatry 1995, 52, 998-1007. [CrossRef]

51. Grace, A. Phasic versus tonic dopamine release and the modulation of dopamine system responsivity: A hypothesis for the etiology of schizophrenia. Neuroscience 1991, 41, 1-24. [CrossRef]

52. Goldman-Rakic, P.S.; Selemon, L.D. Functional and Anatomical Aspects of Prefrontal Pathology in Schizophrenia. Schizophr. Bull. 1997, 23, 437-458. [CrossRef]

53. Weinberger, D.R.; Berman, K.F. Prefrontal function in schizophrenia: Confounds and controversies. Philos. Trans. R. Soc. Lond. B Biol. Sci. 1996, 351, 1495-1503. [CrossRef]

54. Du, X.; Choa, F.-S.; Chiappelli, J.; Wisner, K.M.; Wittenberg, G.; Adhikari, B.; Bruce, H.; Rowland, L.M.; Kochunov, P.; Hong, L.E. Aberrant Middle Prefrontal-Motor Cortex Connectivity Mediates Motor Inhibitory Biomarker in Schizophrenia. Biol. Psychiatry 2019, 85, 49-59. [CrossRef]

55. Walton, E.; Hibar, D.P.; Van Erp, T.G.M.; Potkin, S.G.; Roiz-Santiañez, R.; Crespo-Facorro, B.; Suarez-Pinilla, P.; Van Haren, N.E.M.; De Zwarte, S.M.C.; Kahn, R.S.; et al. Prefrontal cortical thinning links to negative symptoms in schizophrenia via the ENIGMA consortium. Psychol. Med. 2018, 48, 82-94. [CrossRef]

56. Robinson, T.E.; Becker, J.B. Enduring changes in brain and behavior produced by chronic amphetamine administration: A review and evaluation of animal models of amphetamine psychosis. Brain Res. Rev. 1986, 11, 157-198. [CrossRef]

57. Schmidt, W.J.; Beninger, R.J. Behavioural Sensitization in Addiction, Schizophrenia, Parkinson's Disease and Dyskinesia. Neurotox. Res. 2006, 10, 161-166. [CrossRef] [PubMed]

58. Wearne, T.A.; Cornish, J.L. Inhibitory regulation of the prefrontal cortex following behavioral sensitization to amphetamine and/or methamphetamine psychostimulants: A review of GABAergic mechanisms. Prog. Neuro-Psychopharmacol. Biol. Psychiatry 2019, 95, 109681. [CrossRef] [PubMed]

59. Kim, J.; Kornhuber, H.; Schmid-Burgk, W.; Holzmüller, B. Low cerebrospinal fluid glutamate in schizophrenic patients and a new hypothesis on schizophrenia. Neurosci. Lett. 1980, 20, 379-382. [CrossRef]

60. Wachtel, H.; Turski, L. Glutamate: A new target in schizophrenia? Trends Pharmacol. Sci. 1990, 11, 219-220. [CrossRef]

61. Coyle, J.T. NMDA Receptor and Schizophrenia: A Brief History. Schizophr. Bull. 2012, 38, 920-926. [CrossRef] [PubMed]

62. Moghaddam, B.; Adams, B.; Verma, A.; Daly, D. Activation of Glutamatergic Neurotransmission by Ketamine: A Novel Step in the Pathway from NMDA Receptor Blockade to Dopaminergic and Cognitive Disruptions Associated with the Prefrontal Cortex. J. Neurosci. 1997, 17, 2921-2927. [CrossRef]

63. Deutsch, S.I.; Mastropaolo, J.; Schwartz, B.L.; Rosse, R.B.; Morihisa, J.M. A “glutamatergic hypothesis" of schizophrenia. Rationale for pharmacotherapy with glycine. Clin. Neuropharmacol. 1989, 12, 1-13. [CrossRef] [PubMed]

64. Kim, J.; Kornhuber, H.; Brand, U.; Menge, H. Effects of chronic amphetamine treatment on the glutamate concentration in cerebrospinal fluid and brain: Implications for a theory of schizophrenia. Neurosci. Lett. 1981, 24, 93-96. [CrossRef]

65. Swerdlow, N.R. (Ed.) Integrative Circuit Models and Their Implications for the Pathophysiologies and Treatments of the Schizophrenias. In Behavioral Neurobiology of Schizophrenia and Its Treatment; Springer: Berlin/Heidelberg, Germany, 2010; Volume 4, pp. 555-583.

66. Coyle, J.T. The Glutamatergic Dysfunction Hypothesis for Schizophrenia. Harv. Rev. Psychiatry 1996, 3, 241-253. [CrossRef]

67. Lisman, J.E.; Coyle, J.T.; Green, R.W.; Javitt, D.C.; Benes, F.M.; Heckers, S.; Grace, A. Circuit-based framework for understanding neurotransmitter and risk gene interactions in schizophrenia. Trends Neurosci. 2008, 31, 234-242. [CrossRef] [PubMed]

68. Weinberger, D.R. A connectionist approach to the prefrontal cortex. J. Neuropsychiatry Clin. Neurosci. 1993, 5, 241-253. [CrossRef] [PubMed]

69. Friston, K.; Frith, C.D. Schizophrenia: A disconnection syndrome? Clin. Neurosci. 1995, 3, 89-97.

70. Friston, K.; Brown, H.R.; Siemerkus, J.; Stephan, K.E. The dysconnection hypothesis (2016). Schizophr. Res. 2016, 176, 83-94. [CrossRef]

71. Friston, K. Theoretical neurobiology and schizophrenia. Br. Med. Bull. 1996, 52, 644-655. [CrossRef]

72. Bolton, T.A.W.; Wotruba, D.; Buechler, R.; Theodoridou, A.; Michels, L.; Kollias, S.; Rössler, W.; Heekeren, K.; Van De Ville, D. Triple Network Model Dynamically Revisited: Lower Salience Network State Switching in Pre-psychosis. Front. Physiol. 2020, 11, 66. [CrossRef] [PubMed]

73. Menon, V. Salience Network. Brain Mapping; Elsevier: Amsterdam, The Netherlands, 2015; pp. 597-611. 
74. Buckner, R.L. The serendipitous discovery of the brain's default network. NeuroImage 2012, 62, 1137-1145. [CrossRef] [PubMed]

75. Shafiei, G.; Zeighami, Y.; Clark, C.A.; Coull, J.T.; Nagano-Saito, A.; Leyton, M.; Dagher, A.; Mišić, B. Dopamine Signaling Modulates the Stability and Integration of Intrinsic Brain Networks. Cereb. Cortex 2019, 29, 397-409. [CrossRef] [PubMed]

76. Buckner, R.L.; Andrews-Hanna, E.J.R.; Schactera, D.L. The brain's default network: Anatomy, function, and relevance to disease. Ann. N. Y. Acad. Sci. 2008.

77. Greicius, M.D.; Krasnow, B.; Reiss, A.L.; Menon, V. Functional connectivity in the resting brain: A network analysis of the default mode hypothesis. Proc. Natl. Acad. Sci. USA 2003, 100, 253-258. [CrossRef]

78. Uddin, L.Q.; Yeo, B.T.T.; Spreng, R.N. Towards a Universal Taxonomy of Macro-scale Functional Human Brain Networks. Brain Topogr. 2019, 32, 926-942. [CrossRef]

79. Krmpotich, T.D.; Tregellas, J.R.; Thompson, L.L.; Banich, M.T.; Klenk, A.M.; Tanabe, J.L. Resting-state activity in the left executive control network is associated with behavioral approach and is increased in substance dependence. Drug Alcohol Depend. 2013, 129, 1-7. [CrossRef] [PubMed]

80. Seeley, W.W.; Menon, V.; Schatzberg, A.F.; Keller, J.; Glover, G.H.; Kenna, H.; Reiss, A.L.; Greicius, M.D. Dissociable Intrinsic Connectivity Networks for Salience Processing and Executive Control. J. Neurosci. 2007, 27, 2349-2356. [CrossRef]

81. Fox, M.D.; Snyder, A.Z.; Vincent, J.L.; Corbetta, M.; Van Essen, D.C.; Raichle, M.E. From The Cover: The human brain is intrinsically organized into dynamic, anticorrelated functional networks. Proc. Natl. Acad. Sci. USA 2005, 102, 9673-9678. [CrossRef] [PubMed]

82. Binder, J.R.; Frost, J.A.; Hammeke, T.A.; Bellgowan, P.S.; Rao, S.M.; Cox, R.W. Conceptual processing during the conscious resting state. A functional MRI study. J. Cogn. Neurosci. 1999, 11, 80-95. [CrossRef]

83. Menon, V. Large-scale brain networks and psychopathology: A unifying triple network model. Trends Cogn. Sci. 2011, 15, 483-506. [CrossRef]

84. Williamson, P. Are Anticorrelated Networks in the Brain Relevant to Schizophrenia? Schizophr. Bull. 2007, 33, 994-1003. [CrossRef]

85. Stone, J.M.; Morrison, P.D.; Pilowsky, L.S. Glutamate and dopamine dysregulation in schizophrenia-A synthesis and selective review. J. Psychopharmacol. 2007, 21, 440-452. [CrossRef]

86. Olney, J.W.; Newcomer, J.W.; Farber, N. NMDA receptor hypofunction model of schizophrenia. J. Psychiatr. Res. 1999, 33, 523-533. [CrossRef]

87. Bleuler, E. Dementia Praecox or the Group of Schizophrenias; International Universities Press: Oxford, UK, $1950 ;$ p. 548.

88. Weinberger, D.R. Implications of Normal Brain Development for the Pathogenesis of Schizophrenia. Arch. Gen. Psychiatry 1987, 44, 660-669. [CrossRef]

89. Murray, R.; Lewis, S. Is schizophrenia a neurodevelopmental disorder? Br. Med. J. Clin. Res. Ed. 1987, 295, 681-682. [CrossRef] [PubMed]

90. Kulhara, P.; Gupta, S. What is schizophrenia: A neurodevelopmental or neurodegenerative disorder or a combination of both? A critical analysis. Indian J. Psychiatry 2010, 52, 21-27. [CrossRef]

91. Goldman-Rakic, P.S.; Leranth, C.; Williams, S.M.; Mons, N.; Geffard, M. Dopamine synaptic complex with pyramidal neurons in primate cerebral cortex. Proc. Natl. Acad. Sci. USA 1989, 86, 9015-9019. [CrossRef]

92. Mukherjee, A.; Carvalho, F.; Eliez, S.; Caroni, P. Long-Lasting Rescue of Network and Cognitive Dysfunction in a Genetic Schizophrenia Model. Cell 2019, 178, 1387-1402. [CrossRef]

93. Perkins, D.O.; Gu, H.; Boteva, K.; Lieberman, J.A. Relationship Between Duration of Untreated Psychosis and Outcome in First-Episode Schizophrenia: A Critical Review and Meta-Analysis. Am. J. Psychiatry 2005, 162, 1785-1804. [CrossRef] [PubMed]

94. Aryutova, K.; Paunova, R.; Kandilarova, S.; Todeva-Radneva, A.; Stoyanov, D. Implications from translational cross-validation of clinical assessment tools for diagnosis and treatment in psychiatry. World J. Psychiatry 2021, 11, 169-180. [CrossRef] [PubMed]

95. Zhuo, C.; Zhu, J.; Wang, C.; Qu, H.; Ma, X.; Tian, H.; Liu, M.; Qin, W. Brain structural and functional dissociated patterns in schizophrenia. BMC Psychiatry 2017, 17, 45. [CrossRef]

96. Van Erp, T.G.M.; Hibar, D.P.; Rasmussen, J.M.; Glahn, D.C.; Pearlson, G.D.; Andreassen, O.A.; Agartz, I.; Westlye, L.T.; Haukvik, U.K.; Dale, A.M.; et al. Subcortical brain volume abnormalities in 2028 individuals with schizophrenia and 2540 healthy controls via the ENIGMA consortium. Mol. Psychiatry 2016, 21, 547-553. [CrossRef] [PubMed]

97. Chang, M.; Womer, F.Y.; Bai, C.; Zhou, Q.; Wei, S.; Jiang, X.; Geng, H.; Zhou, Y.; Tang, Y.; Wang, F. Voxel-Based Morphometry in Individuals at Genetic High Risk for Schizophrenia and Patients with Schizophrenia during Their First Episode of Psychosis. PLoS ONE 2016, 11, e0163749. [CrossRef]

98. Wright, I.C.; Rabe-Hesketh, S.; Woodruff, P.W.; David, A.S.; Murray, R.; Bullmore, E. Meta-Analysis of Regional Brain Volumes in Schizophrenia. Am. J. Psychiatry 2000, 157, 16-25. [CrossRef]

99. Stoyanov, D.; Kandilarova, S.; Aryutova, K.; Paunova, R.; Todeva-Radneva, A.; Latypova, A.; Kherif, F. Multivariate Analysis of Structural and Functional Neuroimaging Can Inform Psychiatric Differential Diagnosis. Diagnostics 2021, 11, 19. [CrossRef] [PubMed]

100. Shepherd, A.M.; Matheson, S.L.; Laurens, K.; Carr, V.J.; Green, M. Systematic Meta-Analysis of Insula Volume in Schizophrenia. Biol. Psychiatry 2012, 72, 775-784. [CrossRef]

101. Goodkind, M.; Eickhoff, S.B.; Oathes, D.; Jiang, Y.; Chang, A.; Jones-Hagata, L.B.; Ortega, B.N.; Zaiko, Y.V.; Roach, E.L.; Korgaonkar, M.; et al. Identification of a Common Neurobiological Substrate for Mental Illness. JAMA Psychiatry 2015, 72, 305-315. [CrossRef] [PubMed] 
102. Sheffield, J.M.; Rogers, B.P.; Blackford, J.U.; Heckers, S.; Woodward, N.D. Insula functional connectivity in schizophrenia. Schizophr. Res. 2020, 220, 69-77. [CrossRef]

103. Lee, S.-H.; Niznikiewicz, M.; Asami, T.; Otsuka, T.; Salisbury, D.F.; Shenton, M.E.; McCarley, R.W. Initial and Progressive Gray Matter Abnormalities in Insular Gyrus and Temporal Pole in First-Episode Schizophrenia Contrasted With First-Episode Affective Psychosis. Schizophr. Bull. 2016, 42, 790-801. [CrossRef]

104. Mier, D.; Lis, S.; Zygrodnik, K.; Sauer, C.; Ulferts, J.; Gallhofer, B.; Kirsch, P. Evidence for altered amygdala activation in schizophrenia in an adaptive emotion recognition task. Psychiatry Res. 2014, 221, 195-203. [CrossRef] [PubMed]

105. Goghari, V.M.; Sanford, N.; Spilka, M.J.; Woodward, T.S. Task-Related Functional Connectivity Analysis of Emotion Discrimination in a Family Study of Schizophrenia. Schizophr. Bull. 2017, 43, 1348-1362. [CrossRef]

106. Belge, J.-B.; Maurage, P.; Mangelinckx, C.; LeLeux, D.; Delatte, B.; Constant, E. Facial decoding in schizophrenia is underpinned by basic visual processing impairments. Psychiatry Res. 2017, 255, 167-172. [CrossRef]

107. Whitfield-Gabrieli, S.; Thermenos, H.W.; Milanovic, S.; Tsuang, M.T.; Faraone, S.; McCarley, R.; Shenton, M.E.; Green, A.I.; Nieto-Castanon, A.; LaViolette, P.; et al. Hyperactivity and hyperconnectivity of the default network in schizophrenia and in first-degree relatives of persons with schizophrenia. Proc. Natl. Acad. Sci. USA 2009, 106, 1279-1284. [CrossRef] [PubMed]

108. Stoyanov, D.; Aryutova, K.; Kandilarova, S.; Paunova, R.; Arabadzhiev, Z.; Todeva-Radneva, A.; Kostianev, S.; Borgwardt, S. Diagnostic Task Specific Activations in Functional MRI and Aberrant Connectivity of Insula with Middle Frontal Gyrus Can Inform the Differential Diagnosis of Psychosis. Diagnostics 2021, 11, 95. [CrossRef]

109. Nekovarova, T.; Fajnerova, I.; Horáček, J.; Spaniel, F. Bridging disparate symptoms of schizophrenia: A triple network dysfunction theory. Front. Behav. Neurosci. 2014, 8, 171. [CrossRef]

110. Zhou, L.; Pu, W.; Wang, J.; Liu, H.; Wu, G.; Liu, C.; Mwansisya, T.E.; Tao, H.; Chen, X.; Huang, X.; et al. Inefficient DMN Suppression in Schizophrenia Patients with Impaired Cognitive Function but not Patients with Preserved Cognitive Function. Sci. Rep. 2016, 6, 21657. [CrossRef]

111. Aryutova, K.; Paunova, R.; Kandilarova, S.; Maes, M.; Stoyanova, K.; Stoyanov, D. Differential Aberrant Connectivity of Precuneus and Anterior Insula May Underpin the Diagnosis of Schizophrenia and Mood Disorders. WJP 2021, in press.

112. Modinos, G.; Costafreda, S.G.; van Tol, M.-J.; McGuire, P.; Aleman, A.; Allen, P. Neuroanatomy of auditory verbal hallucinations in schizophrenia: A quantitative meta-analysis of voxel-based morphometry studies. Cortex 2013, 49, 1046-1055. [CrossRef] [PubMed]

113. Chan, R.C.K.; Di, X.; McAlonan, G.; Gong, Q. Brain Anatomical Abnormalities in High-Risk Individuals, First-Episode, and Chronic Schizophrenia: An Activation Likelihood Estimation Meta-analysis of Illness Progression. Schizophr. Bull. 2011, 37, 177-188. [CrossRef] [PubMed]

114. Von Zerssen, D.; Koeller, D.M. Paranoid-Depressivitäts-Skala (PD-S); Beltz: Weinheim, Germany, 1976.

115. Pearlson, G.D.; Calhoun, V. Structural and Functional Magnetic Resonance Imaging in Psychiatric Disorders. Can. J. Psychiatry 2007, 52, 158-166. [CrossRef] [PubMed]

116. Menon, V.; Uddin, L.Q. Saliency, switching, attention and control: A network model of insula function. Brain Struct. Funct. 2010, 214, 655-667. [CrossRef]

117. Goulden, N.; Khusnulina, A.; Davis, N.J.; Bracewell, R.M.; Bokde, A.L.; McNulty, J.P.; Mullins, P.G. The salience network is responsible for switching between the default mode network and the central executive network: Replication from DCM. NeuroImage 2014, 99, 180-190. [CrossRef]

118. Holtzheimer, P.E.; Mayberg, H.S. Deep Brain Stimulation for Psychiatric Disorders. Annu. Rev. Neurosci. 2011, 34, $289-307$. [CrossRef]

119. Khalili-Mahani, N.; Rombouts, S.A.; Van Osch, M.J.; Duff, E.P.; Carbonell, F.; Nickerson, L.D.; Becerra, L.; Dahan, A.; Evans, A.C.; Soucy, J.-P.; et al. Biomarkers, designs, and interpretations of resting-state fMRI in translational pharmacological research: A review of state-of-the-Art, challenges, and opportunities for studying brain chemistry. Hum. Brain Mapp. 2017, 38, $2276-2325$. [CrossRef]

120. Vollenweider, F.; Leenders, K.; Scharfetter, C.; Antonini, A.; Maguire, P.; Missimer, J.; Angst, J. Metabolic hyperfrontality and psychopathology in the ketamine model of psychosis using positron emission tomography (PET) and [18F]fluorodeoxyglucose (FDG). Eur. Neuropsychopharmacol. 1997, 7, 9-24. [CrossRef]

121. Lahti, A.C.; Holcomb, H.H.; Medoff, D.R.; Tamminga, C.A. Ketamine activates psychosis and alters limbic blood flow in schizophrenia. NeuroReport 1995, 6, 869-872. [CrossRef]

122. Hartvig, P.; Valtysson, J.; Lindner, K.-J.; Kristensen, J.; Karlsten, R.; Gustafsson, L.L.; Persson, J.; Svensson, J.O.; Øye, I.; Antoni, G.; et al. Central nervous system effects of subdissociative doses of (S)-ketamine are related to plasma and brain concentrations measured with positron emission tomography in healthy volunteers. Clin. Pharmacol. Ther. 1995, 58, 165-173. [CrossRef]

123. Fowler, J.; MacGregor, R.; Wolf, A.; Arnett, C.; Dewey, S.; Schlyer, D.; Christman, D.; Logan, J.; Smith, M.; Sachs, H.; et al. Mapping human brain monoamine oxidase A and B with 11C-labeled suicide inactivators and PET. Science 1987, 235, 481-485. [CrossRef] [PubMed]

124. Volkow, N.D.; Fowler, J.S.; Logan, J.; Gatley, S.J.; Dewey, S.L.; MacGregor, R.R.; Schlyer, D.J.; Pappas, N.; King, P.; Wang, G.J. Carbon-11-cocaine binding compared at subpharmacological and pharmacological doses: A PET study. J. Nucl. Med. 1995, 36, 1289-1297. 
125. Jenkins, B.G. Pharmacologic magnetic resonance imaging (phMRI): Imaging drug action in the brain. NeuroImage 2012, 62, 1072-1085. [CrossRef]

126. Wandschneider, B.; Koepp, M.J. Pharmaco fMRI: Determining the functional anatomy of the effects of medication. NeuroImage Clin. 2016, 12, 691-697. [CrossRef]

127. Borsook, D.; Becerra, L.; Hargreaves, R. A role for fMRI in optimizing CNS drug development. Nat. Rev. Drug Discov. 2006, 5 , 411-425. [CrossRef]

128. Nathan, P.J.; Phan, K.L.; Harmer, C.J.; Mehta, M.A.; Bullmore, E.T. Increasing pharmacological knowledge about human neurological and psychiatric disorders through functional neuroimaging and its application in drug discovery. Curr. Opin. Pharmacol. 2014, 14, 54-61. [CrossRef]

129. Stoianov, D.S. Validation Theory-from basic neuroscience to pharmacopsychology. S. Afr. J. Psychiatry 2007, $13,116$. 